\title{
Effect of a Light-Emitting Diode on Composite Polymerization Shrinkage and Hardness
}

\author{
BRYAN NAKFOOR* \\ PETER YAMAN, DDS, MS ${ }^{\dagger}$ \\ JOSEPH DENNISON, DDS, MS ${ }^{\dagger}$ \\ ALBERTO HERRERO, DDS ${ }^{\dagger}$
}

\section{ABSTRACT}

Purpose: This study evaluated the effect of light-emitting diodes (LEDs) on polymerization shrinkage and bottom-to-top hardness ratios of composites.

Materials and Methods: Six LEDs (Elipar FreeLight, 3M ESPE, St. Paul, MN, USA; Versalux, Centrix, Shelton, CT, USA; Ultra-Lume LED2, Ultradent, South Jordan, UT, USA; Zap LED only, CMSDental/Soft-Core Texas, North Richland Hills, TX, USA; Zap dual light; and L.E.Demetron I, Kerr Manufacturing Inc., Orange, CA, USA) and a quartz-tungsten-halogen (QTH) light (Optilux 501, Kerr Manufacturing Inc.) were tested. Ten specimens each of a microhybrid (Point 4, Kerr Manufacturing, Inc.) and a hybrid (Filtek Z250, 3M ESPE, St. Paul, MN, USA) composite, measuring $2 \mathrm{~mm}$ thick by $5 \mathrm{~mm}$ in diameter, were polymerized using each of the lights. Linear shrinkage was recorded using a contactless displacement instrument. Ten specimens were also polymerized with each light to determine the Knoop hardness number $(\mathrm{KHN})$ at the top and bottom surfaces.

Results: For the microhybrid, Zap dual light had the least volumetric shrinkage $2.08 \%( \pm 0.33)$ and Elipar FreeLight had the highest 3.02\% ( \pm 0.73$)$. There was no significant difference $(p \leq .05)$ in shrinkage for the LEDs when compared with the Optilux 501. The hybrid showed the least amount of shrinkage with the L.E.Demetron I, $1.42 \%( \pm 0.12)$, and the greatest with the Zap dual light, $2.47 \%( \pm 0.31)$. The Ultra-Lume LED2 $(p \leq .05)$ and Zap LED and dual light $(p \leq .001)$ had significantly greater shrinkage than did the Optilux 501. Zap LED had the lowest depth of cure with a bottom KHN of $11.46( \pm 2.71)$ and 33.62 ( \pm 3.57$)$ for the microhybrid and hybrid, respectively. The L.E.Demetron I had the highest bottom hardness value for the microhybrid, with a value of 40.65 ( \pm 1.50 ). The Optilux 501 had the highest bottom hardness value for the hybrid, with a value of $62.03( \pm 0.82)$. The Zap LED and dual light and Versalux lights had significantly lower bottom-to-top hardness ratios than did the QTH ( $p \leq .001)$ with the microhybrid.

Conclusions: There was no statistically significant difference in shrinkage for the microhybrid with any of the lights tested. The hybrid, however, showed significantly less shrinkage with the halogen compared with the Ultra-Lume LED2 and Zap LED and dual light. All LEDs had equal or lower bottom hardness values than did the QTH, except for L.E.Demetron I with the microhybrid.

\section{CLINICAL SIGNIFICANCE}

LEDs are becoming a popular option for curing composite materials, but many of the lights may have inadequate output levels. This study reveals that low output may result in incomplete polymerization and could lead to problems associated with reduced longevity or failure of the restoration.

(J Esthet Restor Dent 17:110-117, 2005) 
$\mathrm{T}$ he use of light-cured composite has dramatically increased in the past few years as a response to an increased demand for esthetic restorations. Light-cured materials possess a unique advantage over those that are chemically cured because they allow the dentist sufficient working time to manipulate the material. This advantage has resulted in light polymerized products that affect all phases of dentistry: restorative materials, cements, veneers, and provisional restorations. This effect is possibly due to the presence of photoinitiators, most of which absorb light in the blue range (450-500 nm). A quartztungsten-halogen (QTH) light source is the predominant type of light used to polymerize these materials. ${ }^{1}$ However, in an effort to decrease exposure time and maintain depth of cure and physical properties of materials, more powerful lights, such as lasers and plasma arc sources, have been developed. The most recent light source type is the blue light-emitting diode (LED).

For maximum polymerization it is important that the light source emit radiation in wavelengths useful to the photoinitiators. ${ }^{1}$ Polymerization shrinkage and variation in depth of cure are properties affected by the type of light source. ${ }^{1}$ Polymerization shrinkage must be minimized because it is a potential cause of tensile stress between the restoration and the tooth. ${ }^{2}$ Significant improvement in marginal adaptation was noted when resins were exposed to two different light intensities: a lower value for 30 seconds and then a higher value for 30 seconds. It was concluded that polymerization occurred at a reduced rate, which allowed for increased material flow while, at the same time, reducing contraction stress. ${ }^{3}$

Composite restorations not maximally polymerized may develop marginal gaps allowing leakage of oral fluids, leading to postoperative sensitivity and discoloration. ${ }^{1}$ Composites with a lower degree of resin conversion have resulted in bond failures, postoperative sensitivity, marginal staining, and recurrent caries. ${ }^{4,5}$ It is therefore important that the light source used adequately polymerizes the variety of restorative materials being used.

The effects of variable light intensity on composite shrinkage have been examined. A QTH source was used with two different sequences of increasing light intensity. One sequence was $25 \%$ intensity for 20 seconds, $50 \%$ intensity for 10 seconds, and $100 \%$ intensity for 10 seconds. The other sequence was $25 \%$ intensity for 10 seconds, $50 \%$ intensity for 10 seconds, and $100 \%$ intensity for 20 seconds. It was concluded that an initial light intensity of $25 \%$ reduced polymerization shrinkage in both sequences. ${ }^{6}$ The reduced shrinkage seen with the use of soft-start techniques was due to lower contraction strain and reduced stress. ${ }^{7}$ This reduction of stress and strain helps maintain margin seal and integrity. ${ }^{8,9}$

A QTH light source produces a wide spectral emission, including light in the visible spectrum, and then uses filters to eliminate all wavelengths except blue. ${ }^{10}$ These lights are available with variations in power density as well as exposure modes. Some have a constant light output, whereas others have an initial low output that ramps up to maximum intensity. ${ }^{11}$ The depth of cure of a composite restoration can be affected by controlling the light intensity. The surface of a composite closest to the light source has the highest conversion, whereas the surface farthest away from the light source has the lowest. ${ }^{11}$ Maximum wear resistance of a composite restoration requires that the composite be polymerized to its maximum extent. ${ }^{12}$

The effect of light intensity on composite microhardness has been investigated using different light intensities that were achieved by varying the distance between the light tip and the composite. Power density was measured using a radiometer placed the same distance from the tip of the light as were the specimens. It was concluded that top hardness was unaffected by power density and that bottom hardness declined as power density decreased. ${ }^{11}$ It has also been shown that LED light-curing units produce significantly lower top and bottom surface hardness values than do conventional halogen light-curing units. ${ }^{13}$ 
Others have also evaluated the depth of cure of composites exposed to varying light intensities. They concluded that the final 20 seconds of exposure should be at full light intensity to maintain ideal depth of cure. ${ }^{6}$ These results support the claim by Rueggeberg and colleagues that when curing a $2 \mathrm{~mm}$ or greater thickness of composite, light intensity and exposure duration are the greatest influences on resin cure. ${ }^{14} \mathrm{~A}$ power density of at least $300 \mathrm{~mW} / \mathrm{cm}^{2}$ is needed to adequately cure a $2 \mathrm{~mm}$ thick increment of composite. ${ }^{15}$

Polymerization shrinkage of composite has been measured using a linometer as well as a mercury dilatometer. ${ }^{16,17}$ No statistical difference in values was found between the two methods. The linometer was found to be insensitive to temperature fluctuations and easy to use in the measurement of linear polymerization shrinkage. ${ }^{6,17}$
The purpose of this study was to evaluate polymerization shrinkage and surface microhardness of composites exposed to a variety of LEDs and a conventional QTH unit.

\section{MATERIALS AND METHODS}

The first part of this study measured the linear polymerization shrinkage, and the second measured composite depth of cure. Each part required the fabrication of 14 groups of 10 specimens each. A microhybrid (Point 4 [Kerr Manufacturing, Inc., Orange, CA, USA], shade A1, lot no. 204B31) and a hybrid composite (Filtek Z250 [3M ESPE, St. Paul, MN, USA], shade A1, lot no. 20020419, 3M ID no. 70-20102225-1) were used. The light-curing units used, their manufacturer, and their power density are listed in Table 1 . The Optilux 501, representative of standard lights, was selected as the QTH reference. The power density of each light was measured before the study using a handheld dental curing light radiometer (Cure Rite Radiometer [EFOS, Inc., Williamsville, NY, USA], model no. 8000) in milliwatts per square centimeter at $470 \mathrm{~nm} \pm 10 \%$.

\section{Part 1: Polymerization Shrinkage} The specimens consisted of uncured composite in a disk shape with a diameter of 5 to $8 \mathrm{~mm}$ and a thickness of 1.5 to $2 \mathrm{~mm}$. Specimens were flattened on a glass slide coated with a separating medium (Al-Cote, Caulk/Dentsply Company, Milford, $\mathrm{DE}, \mathrm{USA}$ ) to allow the composite to shrink freely without being affected by surface adhesion. An aluminum target $10 \mathrm{~mm}$ in diameter and $1 \mathrm{~mm}$ thick, which was also coated, was placed on top of the specimen. This assembly was mounted in a vertical position to allow gravity to maintain the position of the target on the specimen. The target and specimen were positioned at a standard offset distance of $13 \mu \mathrm{m}$ and within the

\section{TABLE 1. CURING LIGHTS AND POWER DENSITIES.}

\begin{tabular}{|c|c|c|c|}
\hline Lights & Manufacturer & Power Density $\left(\mathrm{mW} / \mathrm{cm}^{2}\right)$ & Light Type \\
\hline Elipar FreeLight & 3M ESPE, St. Paul, MN, USA & 332 & LED \\
\hline Versalux & Centrix, Shelton, CT, USA & 104 & LED \\
\hline Ultra-Lume LED2 & Ultradent, South Jordan, UT, USA & 449 & LED \\
\hline Zap light (LED only) & $\begin{array}{l}\text { CMS-Dental/Soft-Core Texas, North Richland } \\
\text { Hills, TX, USA }\end{array}$ & 28 & LED \\
\hline ZAP light* (dual mode) & CMS-Dental/Soft-Core Texas & 301 & LED and QTH \\
\hline L.E.Demetron I & Kerr Manufacturing Inc., Orange, CA, USA & 820 & LED \\
\hline Optilux 501 & Kerr Manufacturing Inc. & 822 & QTH \\
\hline
\end{tabular}


$1 \mathrm{~mm}$ measurement range below a sensor $($ Type $=4 \mathrm{U})$ connected to a contactless measurement system $(\mathrm{K} \mu \mathrm{DA}$, Kaman Instrumentation Corp, Colorado Springs, CO, USA). This system precisely determines the position of a target relative to the system sensor via the use of electric current.

Seventy specimens of each composite were prepared and separated into seven groups of 10 specimens each. All specimens were positioned and exposed for 40 seconds using one of the curing lights, except the Zap dual light. The Zap dual light was activated in the dual mode, whereby the specimen was exposed for 5 seconds in LED mode and 12 seconds in dual (LED + halogen) mode. The distal end of the light guides were attached to a stand and held within $1 \mathrm{~mm}$ of the underside of a glass slide, thus standardizing the position of each light unit for all specimens (Figure 1).

The measuring system was calibrated with a standard $13 \mu \mathrm{m}$ offset at the beginning of each measurement period. First a three-point calibration was performed on the hardware establishing the minimum $(0 \mu \mathrm{m})$, midpoint $(500 \mu \mathrm{m})$, and maximum $(1,000 \mu \mathrm{m})$ distances to be measured. Then, a 21-point calibration of the software was performed, correlating change in probe response every $50 \mu \mathrm{m}$ from the minimum distance $(0 \mu \mathrm{m})$ through the maximum distance $(1,000 \mu \mathrm{m})$. The linear shrinkage data was recorded

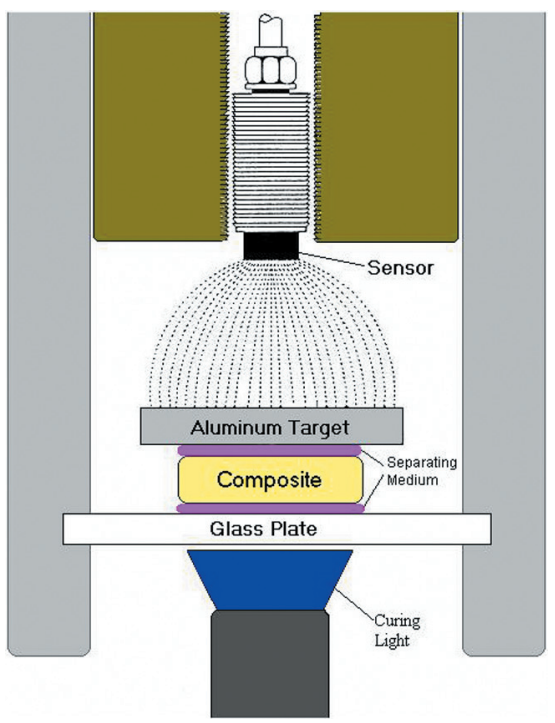

Figure 1. Schematic diagram of setup used to measure linear polymerization.

as $\Delta \mathrm{L}$. The percentage of linear shrinkage (Lin \%) was calculated using the following formula ${ }^{6,16}$ :

$$
\operatorname{Lin} \%=\frac{\Delta \mathrm{L}}{\mathrm{L}+\Delta \mathrm{L}} \times 100
$$

where $\Delta \mathrm{L}$ is the recorded displacement in micrometers and $\mathrm{L}$ is the thickness of the specimen in micrometers immediately after polymerization. The Lin \% was converted into a volumetric value $(\mathrm{Vol} \%)$ using the following formula ${ }^{6,16}$ :

$$
\begin{aligned}
\operatorname{Vol} \%= & 3 \operatorname{Lin} \%-0.03(\operatorname{Lin} \%)^{2} \\
& +0.0001(\operatorname{Lin} \%)^{3}
\end{aligned}
$$

in which the last term is negligible.

\section{Part 2: Bottom-to-Top \\ Hardness Ratio}

Specimens were fabricated in a stainless steel mold, $8 \mathrm{~mm}$ in diameter and $2 \mathrm{~mm}$ thick. Seventy specimens of each composite were fabricated and separated into seven groups of 10 specimens each. Each specimen was prepared between two glass slides and exposed from the top for 40 seconds using each of the curing lights. The Zap light was again used in the dual mode.

Immediately following the last exposure, the specimen was removed and a dot was placed on the top of the specimen that faced the curing light. Then each specimen was numbered and placed in a dark container for 24 hours. Surface microhardness was determined using a microhardness machine (Knoop indenter, Tukon Tester, Wilson Instruments, New York, NY, USA), with a $200 \mathrm{~g}$ load applied for 40 seconds. Three hardness measurements were taken on both top and bottom surfaces of each specimen and averaged to provide the hardness value for each surface. The bottom-to-top (b:t) ratio for each specimen was then computed using the mean bottom hardness divided by the mean top hardness.

A two-way analysis of variance (ANOVA) for shrinkage and hardness values as well as an interaction effect was applied. This was followed by one-way ANOVA testing to determine whether there was a significant difference in parameter values among the curing lights for each type of composite. A two-tailed Dunnett's $t$-test was used to determine significant differences, with the Optilux 501 as the control. A Student's $t$-test was used to compare 
TABLE 2. MEAN PERCENTAGE OF VOLUMETRIC SHRINKAGE (SD).

\begin{tabular}{lllc} 
Light & With Point 4* & With Z250* & $p<.05$ \\
Versalux & $2.97(0.31)^{\mathrm{a}}$ & $1.95(0.32)^{\mathrm{a}}$ & $\mathrm{Y}$ \\
Elipar FreeLight & $3.02(0.73)^{\mathrm{a}}$ & $1.89(0.22)^{\mathrm{a}}$ & $\mathrm{Y}$ \\
Ultra-Lume LED2 & $2.77(0.69)^{\mathrm{a}}$ & $2.09(0.39)^{\mathrm{b}}$ & $\mathrm{Y}$ \\
ZAP light (LED only) & $2.44(0.43)^{\mathrm{a}}$ & $2.46(0.41)^{\mathrm{b}}$ & $\mathrm{N}$ \\
ZAP light (dual mode) ${ }^{\dagger}$ & $2.08(0.33)^{\mathrm{a}}$ & $2.47(0.31)^{\mathrm{b}}$ & $\mathrm{Y}$ \\
L.E.Demetron I $^{\text {Optilux 501 }}$ & $2.47(0.23)^{\mathrm{a}}$ & $1.42(0.12)^{\mathrm{a}}$ & $\mathrm{Y}$ \\
\hline
\end{tabular}

LED = light-emitting diode; $\mathrm{N}=$ no; $\mathrm{Y}=$ yes.

"Within a column, values with the same letter were not significantly different $(p<.05)$ using Optilux 501 as reference.

†The Zap light is a combination LED and halogen light. Manufacturer's recommended exposure time: $5 \mathrm{~s}$ of LED and $12 \mathrm{~s}$ of dual mode (LED and halogen).

shrinkage and hardness of both composites for each light.

\section{RESULTS}

Polymerization shrinkage values are listed in Table 2. For Point 4, shrinkage values ranged from a high of $3.02 \%$ with the Elipar FreeLight to a low of $2.08 \%$ with the Zap dual light. For Z250, shrinkage values ranged from a high of $2.47 \%$ with the Zap dual light to a low of $1.42 \%$ with the L.E.Demetron I.
The effects of the composites and curing lights were assessed using a two-way ANOVA, with the results indicating significant differences for both variables and the interaction at $p<.05$. Using a one-way ANOVA, there was a significant difference $(p<.05)$ in shrinkage for Point 4. But, the two-tailed Dunnett's $t$-test for the lights tested indicated no difference $(p<.05)$ for the LEDs when compared with the Optilux 501. For Z250, the one-way ANOVA showed a significant difference at $p<.001$. The two-tailed Dunnett's $t$-test showed that the Ultra-Lume $(p<.05)$ and Zap $(p<.001)$ LED and dual light resulted in significantly greater shrinkage than did the Optilux 501. There was significantly greater shrinkage for Point 4 over Z250 for all lights tested except the Zap LED and dual light. The Zap LED was not significantly different; the Zap dual light was significantly lower for Point 4.

Hardness values are presented in Table 3 and include the b:t depth-ofcure ratio. The Point 4 top hardness values ranged from a minimum of 20.58 ( \pm 3.69) Knoop hardness number $(\mathrm{KHN})$ using the Zap LED to a maximum of $44.29( \pm 1.01)$ KHN with the Optilux 501. Bottom hardness values ranged from a minimum of $11.46( \pm 2.71) \mathrm{KHN}$ with the Zap LED to a maximum of $40.65( \pm 1.50) \mathrm{KHN}$ using the L.E.Demetron I. The b:t ratio ranged from a minimum of 0.56

\begin{tabular}{|c|c|c|c|c|c|c|c|}
\hline \multirow[b]{2}{*}{ Light } & \multicolumn{3}{|c|}{ For Point 4} & \multicolumn{3}{|c|}{ For Z250 } & \multirow[b]{2}{*}{$p<.05$} \\
\hline & Top KHN & Bottom KHN & b:t Ratio* & Top KHN & Bottom KHN & b:t Ratio* & \\
\hline Versalux & $36.16(1.44)$ & $21.20(1.34)$ & $0.59(0.03)^{\mathrm{a}}$ & $52.53(2.29)$ & $42.46(1.85)$ & $0.81(0.04)^{\mathrm{a}}$ & Y \\
\hline Elipar FreeLight & $40.36(2.68)$ & $33.90(3.62)$ & $0.84(0.11)^{\mathrm{b}}$ & $60.19(3.13)$ & $55.12(1.82)$ & $0.92(0.03)^{\mathrm{b}}$ & Y \\
\hline Ultra-Lume LED2 & $42.41(2.08)$ & $38.21(2.82)$ & $0.90(0.07)^{\mathrm{b}}$ & $65.40(1.48)$ & $58.04(1.80)$ & $0.89(0.03)^{\mathrm{a}}$ & $\mathrm{N}$ \\
\hline ZAP light (LED only) & $20.58(3.69)$ & $11.46(2.71)$ & $0.56(0.09)^{\mathrm{a}}$ & $48.72(2.86)$ & $33.62(3.57)$ & $0.69(0.07)^{\mathrm{a}}$ & Y \\
\hline $\mathrm{ZAP}_{\text {light }}(\text { dual mode })^{\dagger}$ & $38.63(1.68)$ & $26.27(0.95)$ & $0.68(0.03)^{\mathrm{a}}$ & $57.69(2.57)$ & $49.17(0.83)$ & $0.85(0.03)^{\mathrm{a}}$ & $\mathrm{Y}$ \\
\hline L.E.Demetron I & $43.14(1.14)$ & $40.65(1.50)$ & $0.94(0.03)^{\mathrm{b}}$ & $64.79(1.10)$ & $60.73(3.38)$ & $0.94(0.04)^{\mathrm{b}}$ & $\mathrm{N}$ \\
\hline Optilux 501 & $44.29(1.01)$ & 40.56 (1.37) & $0.92(0.03)^{b}$ & $65.61(1.15)$ & $62.03(0.82)$ & $0.95(0.01)^{\mathrm{b}}$ & Y \\
\hline
\end{tabular}


with the Zap LED to a maximum of 0.94 using the L.E.Demetron I. For Z250, top hardness values ranged from a minimum of 48.72 $( \pm 2.86) \mathrm{KHN}$ using the Zap LED to a maximum of $65.61( \pm 1.15)$ KHN with the Optilux 501. Bottom hardness values ranged from a minimum of $33.62( \pm 3.57) \mathrm{KHN}$ with the Zap LED to a maximum of $62.03( \pm 0.82) \mathrm{KHN}$ using the Optilux 501. The b:t ratio ranged from a minimum of 0.69 with the Zap LED to a maximum of 0.95 using the Optilux 501. The b:t ratios were compared to the curing lights and composite types using a twoway ANOVA; the results indicated significant differences for both variables and the interaction at $p<.05$. A one-way ANOVA was then performed for each composite's b:t ratio for the light-curing units. For Point 4 the one-way ANOVA showed a significant difference at $p<.001$, and the two-tailed Dunnett's $t$-test showed the Versalux $(p<.001)$, Zap LED $(p<.001)$, and the Zap dual light $(p<.001)$ had significantly lower b:t ratio values compared with the Optilux 501. For Z250 the one-way ANOVA showed a significant difference at $p<.001$, and the two-tailed Dunnett's $t$-test showed the Versalux $(p<.001)$, Ultra-Lume LED2 $(p<.05)$, Zap LED $(p<.001)$, and the Zap dual light $(p<.001)$ had significantly lower $b: t$ ratios than that of the Optilux 501. There was a significant difference in b:t ratio between composites for all lights tested except Ultra-Lume LED2 and L.E.Demetron I.

\section{DISCUSSION}

This study evaluated the polymerization shrinkage and b:t depthof-cure ratio of composites activated with multiple LED light-curing units and a conventional halogen light. The LEDs used in this study did not perform better than the conventional halogen light. If polymerization shrinkage were the only criterion to be considered, then it would be expected that all the lights tested would perform similarly in clinical application.

The one dual light used in this study had mixed results. Point 4 exposed using the Zap dual light had the least shrinkage. This result agrees with the findings of Dennison and colleagues that an initial low light intensity followed by high light intensity reduces polymerization shrinkage. ${ }^{6}$ The Zap LED and dual light and Ultra-Lume LED2 had greater volumetric shrinkage for Z250 than did the QTH. This result could potentially lead to poor marginal integrity, which would disagree with the findings of Uno and Asmussen that light-curing cycle with different intensities, low to high, leads to marginal improvement. ${ }^{3}$ All other lights used showed less volumetric shrinkage with Z250 than with Point 4.

This study revealed significant differences among LED lightcuring units to cure the top and bottom surfaces of a $2 \mathrm{~mm}$ thick composite specimen. All LEDs tested produced a lower surface hardness than did the Optilux 501 halogen light. The L.E.Demetron I, Ultra-Lume LED2, and Elipar FreeLight were within $10 \%$ of the Optilux 501 top hardness value, and the L.E.Demetron I and Ultra-Lume LED2 were within $10 \%$ of the Optilux 501 bottom hardness value. These results agree with Dunn and Bush's finding that LEDs demonstrated lower top and bottom surface hardness compared to conventional halogen lights. ${ }^{13}$

The lights with greatest power density polymerized composite the most at the depth of $2 \mathrm{~mm}$. This result agrees with Pires and colleagues that bottom hardness declines as light intensity declines. ${ }^{11}$ Two of the three light-curing units with external power sources, Optilux 501 and Ultra-Lume LED2, had power densities $>400 \mathrm{~mW} / \mathrm{cm}^{2}$. These lights also had the highest values for top and bottom hardness, which supports Rueggeberg and colleagues' findings that light intensity is one of the greatest influences on resin cure in a specimen thickness of 2 mm or greater. ${ }^{14}$

The Versalux had a power density that was below the recommended output $\left(300 \mathrm{~mW} / \mathrm{cm}^{2}\right)$ and resulted in the second lowest b:t ratio with both composites. The Zap LED performed as expected, owing to the fact that it is designed as a low-intensity LED to be used for the soft-start portion of stepped light curing. 
The b:t ratio used in this study has limitations when comparing the ability of a light-curing unit to maximally polymerize a composite. For example, with Z250, the Elipar FreeLight had a b:t ratio of 0.92 $( \pm 0.03)$, whereas the Ultra-Lume LED2 had a ratio of $0.89( \pm 0.03)$. The Ultra-Lume LED2 had top and bottom hardness values greater than those of the Elipar FreeLight. The b:t ratio using the Ultra-Lume LED2 with Z250, was significantly lower than the same ratio for Optilux 501, even though the top hardness achieved with Ultra-Lume LED2 was within $0.21 \mathrm{KHN}$ of that obtained with Optilux. With Point 4, the L.E.Demetron I had the highest b:t ratio $0.94( \pm 0.03)$, whereas the Optilux 501 had a ratio of $0.92( \pm 0.03)$. The Optilux 501 had a top hardness of 44.29 $( \pm 1.01) \mathrm{KHN}$, and the L.E.Demetron I top hardness was 43.14 $( \pm 1.14) \mathrm{KHN}$. Therefore the b:t ratio may be misleading, and the actual hardness number must be examined to determine a light's ability to adequately polymerize a composite.

\section{CONCLUSIONS}

The following conclusions can be drawn from this study:

- There was no significant difference in polymerization shrinkage between LEDs and the halogen light for the Point 4 composite.

- The Z250 composite cured with the Ultra-Lume LED2, Zap dual light, and Zap LED had signifi- cantly greater shrinkage than occurred with Optilux 501; the Versalux, Elipar FreeLight, and L.E.Demetron I did not produce significantly different results from the Optilux 501.

- All the LEDs had equal or lower bottom hardness values than occurred with the halogen light, for both composites, except for L.E.Demetron I with Point 4.

- All lights produced equal or greater b:t hardness ratios with Z250 than with Point 4.

\section{DISCLOSURE}

The authors do not have any financial interest in the companies whose materials are discussed in this article. Funding was provided by the University of Michigan, School of Dentistry, Student Research Program.

\section{REFERENCES}

1. Craig RG, Powers JM. Restorative dental materials. 11th Ed. St. Louis: C.V. Mosby, 2002

2. Jorgensen KD, Asmussen E, Shimokobe H. Enamel damages caused by contracting restorative resins. Scand J Dent Res 1975; 2:120-122.

3. Uno S, Asmussen A. Marginal adaptation of a restorative resin polymerized at reduced rate. Scand J Dent Res 1991; 5:440-444.

4. Condon JR, Ferrancane JL. Assessing the effect of composite formulation on polymerization stress. J Am Dent Assoc 2000; 4:497-503.

5. Wilson N, Burke F, Mjör I. Reasons for placement and replacement of restorations of direct restorative materials by a select group of practitioners in the United Kingdom. Quintessence Int 1997; 38:245-248.

6. Dennison JB, Yaman P, Seir R, Hamilton JC. Effect on variable light intensity on composite shrinkage. J Prosthet Dent 2000; 5:499-505.

7. Sakaguchi RL, Berge HX. Reduced light energy density decreases post-gel contraction while maintaining degree of conversion in composites. J Dent 1998; 1:695-700.

8. Feilzer AJ, Dooren LH, de Gee AJ, Davidson CL. Influence of light intensity on polymerization shrinkage and integrity of restoration-cavity interface. Eur J Oral Sci $1995 ; 5: 322-326$.

9. Yoshikawa T, Burrow MF, Tagami J. A light curing method for improving marginal sealing and cavity wall adaptation of resin composite restorations. Dent Mater 2001; 4:359-366.

10. O'Brien W. Dental materials and their selection. 3rd Ed. Chicago: Quintessence, 2002.

11. Pires JA, Cvitko E, Denehy GE, Swift EJ Jr. Effects of curing tip distance on light intensity and composite resin microhardness. Quintessence Int 1993; 7:517-521.

12. Ferracane JL, Mitchem JC, Condon JR, Todd R. Wear and marginal breakdown of composites with various degrees of cure. J Dent Res 1997; 8:1508-1516.

13. Dunn WJ, Bush AC. A comparison of polymerization by light-emitting diode and halogen-based light-curing units. J Am Dent Assoc 2002; 3:335-341.

14. Rueggeberg FA, Caughman WF, Curtis JW, Davis HC. Factors affecting cure at depths within light-activated resin composites. Am J Dent 1993; 2:91-95.

15. Rueggeberg FA, Caughman WF, Curtis JW Jr. Effect of light intensity and exposure duration on cure of resin composite. Oper Dent 1994; 1:26-32.

16. de Gee AF, Fielzer AJ, Davidson CL. True linear polymerization shrinkage of unfilled resins and composites determined with a linometer. Dent Mater 1993; 1:11-14.

17. Fielzer AJ, deGee AJ, Davidson C. Curing contraction of composite and glass ionomer cements. J Prosthet Dent 1988; 59:297-300.

Presented at the American Association of Dental Research meeting in San Antonio, TX, USA, March 12-15, 2003.

Reprint requests: Peter Yaman, DDS, MS, University of Michigan, 2066 Dent,

Ann Arbor, MI 48109-1078;

e-mail:pyam@umich.edu

(c)2005 BC Decker Inc 